\title{
Defect of N-Glycosylation Is Not Directly Related to Congenital Disorder of Glycosylation Ia Fibroblast Sensitivity to Staurosporine-Induced Cell Death
}

\author{
GRÉGORY LAVIEU, JEAN-PIERRE FRÉNOY, PATRICE CODOGNO, AND JOËLLE BOTTI
}

INSERM Unité 504, Bâtiment INSERM, 94807 Villejuif Cedex, France

\begin{abstract}
Congenital disorder of glycosylation Ia (CDGIa) is an autosomal recessive disease that is caused by mutations in the gene $P M M 2$ encoding phosphomannomutase, an enzyme that synthesizes mannose-1-phosphate, an important intermediate for the $\mathrm{N}$-glycan biosynthesis. Here, we investigated the susceptibility of CDGIa fibroblasts to cell death induction. CDGIa fibroblasts were more sensitive than control fibroblasts to staurosporineinduced apoptosis. Supplementation with mannose, which corrects $\mathrm{N}$-glycosylation in CDGIa fibroblasts, did not abrogate their higher sensitivity to staurosporine. These results show that the sensitivity of CDGIa fibroblasts to apoptosis is not directly related to their defective N-glycosylation. (Pediatr Res 58: 254-257, 2005)
\end{abstract}

ABSTRACT

\author{
Abbreviations \\ CDGIa, congenital disorder of glycosylation Ia \\ endo $\mathrm{H}$, endo- $\beta$ - $\mathrm{N}$-acetylglucosaminidase $\mathrm{H}$ \\ ER, endoplasmic reticulum \\ LLO, lipid-linked oligosaccharides \\ PARP, poly-(ADP-ribose)polymerase \\ z-VAD-fmk, N-benzyloxycarbonyl-Val-Ala-(DL)Asp- \\ fluoromethylketone
}

Phosphomannomutase (PMM) catalyzes the reversible conversion of mannose-6-phosphate to mannose-1-phosphate. Mannose-1-phosphate is the precursor of guanosine diphospho-mannose and dolichol-P-mannose, two intermediates that are required for the synthesis of lipid-linked oligosaccharides (LLO) before their transfer en bloc onto nascent polypeptides. Mutations in the PMM2 gene are causative of a severe multisystemic disease congenital disorder of glycosylation Ia (CDGIa) (1,2). Clinical presentation of CDGIa comprises moderate to severe neurologic disorders frequently associated with liver and cardiac failures $(3,4)$. Genetic analysis of $P M M 2$ in patients with CDGIa revealed a large number of missense mutations. The lack of patients who are homozygous for the most frequent mutation $\mathrm{R} 141 \mathrm{H}$ suggests that R141H homozygosity may not be compatible with life (5). A proof of the lethality of $\mathrm{R} 141 \mathrm{H}$ homozygosity awaits the generation of

Received July 13, 2004; accepted December 7, 2004.

Correspondence: Joëlle Botti, Ph.D., INSERM Unité 504, Bâtiment INSERM, 16 Avenue Paul Vaillant Couturier, 94807 Villejuif Cedex, France; e-mail: botti@vjf.inserm.fr.

This work was supported by institutional funding from the Institut National de la Santé et de la Recherche Médicale (INSERM) and an INSERM-AFM research network grant (4MR39F) "Réseau de Recherche sur les CDG."

DOI: 10.1203/01.PDR.0000169962.02462.C0 knockout mice (6). It is worth noting that deletion of Sec 53, the Saccharomyces cerevisiae PMM2 homologue, has been reported to be lethal (7). However, to our knowledge, there are no available data on the possible relationship between CDGIa and cell death. These observations led us to investigate the sensitivity to cell death of fibroblasts derived from patients with CDGIa. Here, we show that CDGIa fibroblasts are more sensitive to staurosporine-induced apoptosis than nonpathologic fibroblasts. The higher sensitivity to staurosporine in CDGIa is not abrogated by restoring N-glycosylation by mannose supplementation.

\section{METHODS}

Cell culture. The CDG-Ia and control skin fibroblasts were a gift from T. Dupré and N. Seta (Service de Biochimie A, Hôpital Bichat, Paris, France). They were initially obtained from skin biopsy of two patients (CDGIa-A and CDGIa-B) and two normal subjects (age matched). Fibroblasts were grown in DMEM (GIBCO-BRL, Cergy-Pontoise, France) that contained $5 \mathrm{mM}$ glucose, $10 \% \mathrm{FCS}$, and $1 \%$ penicillin/streptomycin (complete medium) at $37^{\circ} \mathrm{C}$ under $10 \% \mathrm{CO}_{2}$ atmosphere. Diagnosis of CDGIa at the biochemical level was established by demonstrating the presence of hypoglycosylated transferrin and by phosphomannomutase activity measurements $(8,9)$. In patient CDGIa-A, the two alleles of PMM2 gene contained mutations associated with changed $(\mathrm{R} 141 \mathrm{H}$; V231M) positions in the protein, and no enzymatic activity was detectable. In patient CDGIa-B, the PMM activity was $0.6 \mathrm{U} / \mathrm{g}$ protein $(15 \%$ of normal activity), and this was associated with mutations (R123Q; I153T). Both patients presented common clinical features characterized by neurologic symptoms (mental retardation, hypotonia), dysmorphic symptoms (abnormal fat pads and inverted nipples), and systemic manifestations such as pericardial effusions. 
Cell viability. Cells were seeded at a concentration of $3 \times 10^{4}$ cells/well in 24-well plates and incubated in complete medium for $48 \mathrm{~h}$; the cellular stress was initiated by replacement with the same medium that contained staurosporine (Calbiochem/VWR, Fontenay aux Roses, France). When necessary, mannose (Sigma Chemical Co., Saint Quentin Fallavier, France) was supplemented at the final concentration of $1 \mathrm{mM}$. When used, $100 \mu \mathrm{M} \mathrm{z}$-Val-Ala-(DL)Aspfluoromethylketone (z-VAD-fmk; Apotech/Coger, Paris, France) was added $1 \mathrm{~h}$ before the addition of staurosporine and maintained throughout the experiment. Cell viability was estimated by the trypan blue dye exclusion method.

Western blot analysis. Cells were trypsinized and collected by centrifugation (10 min, $1200 \mathrm{~g} / \mathrm{min})$, washed with PBS, and resuspended in lysis buffer 1 [1\% Triton $\mathrm{X}-100,25 \mathrm{mM}$ Tris- $\mathrm{HCl}$ (pH 7.4), $1 \mathrm{mM}$ PMSF, $1 \%$ protease inhibitor cocktail (Sigma Chemical Co.), $1 \mathrm{mM} \mathrm{Na}_{3} \mathrm{VO}_{4}$, and $1 \mathrm{mM} \mathrm{NaF}$ ] for $1 \mathrm{~h}$ at $4^{\circ} \mathrm{C}$. Cell lysates were centrifuged $\left(100,000 \mathrm{~g} / \mathrm{min}, 1 \mathrm{~h}, 4^{\circ} \mathrm{C}\right)$, and supernatants were recovered. Protein concentrations were determined by the bicinchoninic acid method (10) (Pierce/Interchim, Asnières, France) as recommended by the manufacturer. Extracted proteins first were separated in 7.5 or $15 \%$ SDS-PAGE and then electrotransferred onto nitrocellulose membranes. After blocking overnight with nonfat milk, the membranes were incubated with the following antibodies, namely polyclonal of anti-pro and cleaved form of caspase 9 and anti-cleaved caspase 3 from Apoptosis sampler Kit (Cell Signaling Technology, Saint-Quentin-en-Yvelines, France; dilution 1:1000), polyclonal of anti-Grp 78 (Santa Cruz Biotechnology, Santa Cruz, CA; dilution 1:500), polyclonal of anti-Bax (Santa Cruz; dilution 1:200), monoclonal of anti-Bcl-2 clone 124 (Dako, Trappes, France; dilution 1:1000), monoclonal of anti-poly-(ADP-ribose)-polymerase (PARP-1) clone C2-10 (Alexis Biochemicals, San Diego, CA; dilution 1:10000), and monoclonal of anti-actin (MAB 1501; Molecular Probes, Eugene, OR; dilution 1:2000) at $20^{\circ} \mathrm{C}$ for $2 \mathrm{~h}$. Bound primary antibodies were detected by chemiluminescence (ECL; Amersham Biosciences, Orsay, France) using horseradish peroxidase-conjugated secondary antibodies against rabbit or mouse immunoglobulins (Caltag, Burlingame, CA; dilution 1:5000).

Metabolic labeling. Fibroblasts $\left(2 \times 10^{5}\right.$ cells/well $)$ were labelled with $\left[2-{ }^{3} \mathrm{H}\right]$ mannose $\left(7.4 \times 10^{5} \mathrm{~Bq} / \mathrm{mL}\right.$; NEN-Perkin Elmer, Courtaboeuf, France $)$ and $\left[{ }^{35} \mathrm{~S}\right]$ Easy tag labeling mix (methionine+cysteine, $2.2 \times 10^{5} \mathrm{~Bq} / \mathrm{mL}$; $\mathrm{NEN}$-Perkin Elmer) for $1 \mathrm{~h}$ at $37^{\circ} \mathrm{C}$ in DMEM that contained $0.5 \mathrm{mM}$ glucose with or without $1 \mathrm{mM}$ mannose. After removal of the medium, cells were quickly washed three times with ice-cold PBS. The cells then were scraped into PBS and lysed by sonication. Lysates were trichloroacetic acid (TCA)precipitated before and after endo- $\beta$-N-acetylglucosaminidase $\mathrm{H}$ (endo $\mathrm{H}$ ) digestion. TCA-precipitated and TCA-soluble materials were counted and normalized to protein content. Aliquots were used for protein determination by the bicinchoninic acid method. Endo $\mathrm{H}$ digestion $(10 \mathrm{mU} / \mathrm{mL}$; Oxford Glycosystems/Coger, Paris, France) was performed in $0.2 \mathrm{M}$ sodium citrate buffer (pH 5.5) that contained $0.3 \% \mathrm{NP} 40$, for $24 \mathrm{~h}$ at $37^{\circ} \mathrm{C}$.

Isolation and analysis of $\mathbf{L L O}$. Eighty percent confluent fibroblasts were labeled during 30 min with $\left[2-{ }^{3} \mathrm{H}\right]$ mannose $\left(7.4 \times 10^{5} \mathrm{~Bq} / \mathrm{mL}\right.$, NEN-Perkin Elmer) in glucose-free DMEM supplemented with $0.5 \mathrm{mM}$ glucose and $2.5 \%$ fetal calf dialyzed serum. When required, $1 \mathrm{mM}$ mannose was added $24 \mathrm{~h}$ before and during the labeling pulse.

After radiolabeling, cells were rinsed with ice-cold PBS and scraped in extraction buffer [100 mM Tris- $\mathrm{HCl}$ (pH 7.4) and $4 \mathrm{mM} \mathrm{MgCl} 2 /$ methanol, 1:2]. An equal volume of chloroform was added, and samples were shaken. After centrifugation, the chloroform phase was saved. This operation was repeated twice, and chloroform phases were mixed, dried, and hydrolyzed with $20 \mathrm{mM}$ $\mathrm{HCl}$. Samples then were centrifuged and dried, and the resulting pellets were extracted in $\mathrm{H}_{2} \mathrm{O}$ and an equal volume of chloroform/methanol $(5: 1)$. The aqueous phase was saved and desalted on AG-1/AG-50 columns. Finally, samples were resolved by TLC on silica-coated plastic sheets (Merck, Darnstadt, Germany) in n-propyl alcohol/acetic acid/ $\mathrm{H}_{2} \mathrm{O}(3: 3: 2)$ for $42 \mathrm{~h}$. Radioactive components were detected by autoradiography.

DNA fragmentation analysis. Fibroblasts were treated with $500 \mathrm{nM}$ staurosporine for $24 \mathrm{~h}$ with or without $\mathrm{z}-\mathrm{VAD}$-fmk. Floating and adherent cells were collected, rinsed twice with PBS, and resuspended for $1 \mathrm{~h}$ in lysis buffer 2 [1\% Triton $\mathrm{X}-100,50 \mathrm{mM}$ Tris- $\mathrm{HCl}$ (pH 7.4), and 1 mM EDTA]. Cell lysates were treated with ribonuclease $\mathrm{A}(5 \mu \mathrm{g} / \mathrm{mL})$ and proteinase $\mathrm{K}(5 \mu \mathrm{g} / \mathrm{mL})$ at $37^{\circ} \mathrm{C}$ for $3 \mathrm{~h}$. DNA was extracted twice with phenol:chloroform:isoamylic alcohol (25:24:1; v/v/v; GIBCO-BRL). The aqueous phase was collected, and DNA was precipitated with $3 \mathrm{M}$ sodium acetate in $100 \%$ ethanol at $20^{\circ} \mathrm{C}$ overnight. After centrifugation, the pellet was resuspended in Tris EDTA buffer $[10 \mathrm{mM}$ Tris $\mathrm{HCl}(\mathrm{pH} 7.5)$ and $0.1 \mathrm{mM}$ EDTA]. Each sample was electrophoresed on a $1.6 \%$ agarose gel and visualized by ethidium bromide staining.

\section{RESULTS}

Sensitivity of CDGIa fibroblasts to staurosporine-induced cell death. The different cell populations first were exposed to the protein kinase $\mathrm{C}$ inhibitor staurosporine $(500 \mathrm{nM})$, a widely known inducer of apoptosis (11). After $12 \mathrm{~h}$ of treatment, staurosporine induced a loss in viability in both CDGIa and two control population of age-matched fibroblasts. However, the loss of viability was more pronounced in the two CDGIa fibroblast populations (Fig. 1A). When cells were treated with $100 \mathrm{nM}$ staurosporine, reductions of $40-45 \%$ and $65 \%$ in cell viability were observed in controls and CDGIa cells, respectively (Fig. 1B).

Characterization of the staurosporine-induced cell death. In a first set of experiments, we investigated the effect of z-VAD-fmk, a pan caspase inhibitor (12), on staurosporineinduced cytotoxicity. Pretreatment for $1 \mathrm{~h}$ with $100 \mu \mathrm{M} \mathrm{z}$ VAD-fmk before the addition of $500 \mathrm{nM}$ staurosporine dramatically reduced cell death in both CDGIa and control fibroblasts (66 and $75 \%$ of cell survival after $24 \mathrm{~h}$ of staurosporine treatment in CDGIa and control fibroblasts, respectively; Fig. 2A). Similar results were obtained in cells that were treated with $200 \mu \mathrm{M} \mathrm{z}$-VAD-fmk. These data suggest that a caspase-dependent mechanism is mainly responsible for cell death induced by staurosporine in fibroblasts whatever the PMM2 status. Another hallmark of apoptosis is the generation of DNA ladders as a result of internucleosomal fragmentation. DNA ladders were observed in both CDGIa and control fibroblasts that were treated with $500 \mathrm{nM}$ staurosporine for $24 \mathrm{~h}$. The formation of ladders is totally abolished in the presence of z-VAD-fmk (Fig. 2B). As cell death is severely impaired by $z$-VAD-fmk, we next investigated the activation of the initiator caspase 9 and the effector caspase 3. Proteolytic cleavages of caspase 9 and caspase 3 were observed by immunoblotting after staurosporine treatment in both CDGIa and control fibroblasts (Fig. 2C). The proteolytic activation of caspase 3 was confirmed by the analysis of the cleavage of its specific substrate PARP in both cell populations (Fig. 2C). The higher sensitivity of CDGIa fibroblasts to staurosporine is not related to the reduced expression of the antiapoptotic protein Bcl-2

A

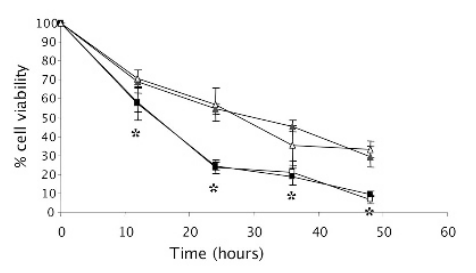

Figure 1. Sensitivity of CDGIa and control fibroblasts to staurosporine. $(A)$ Cells were preincubated in complete medium for $48 \mathrm{~h}$ before the addition of staurosporine $(500 \mathrm{nM})$ for the indicated time. Cell viability was analyzed by the trypan blue exclusion test. (B) Cell viability was estimated after $48 \mathrm{~h}$ of treatment with different staurosporine concentrations. In $A$ and $B$, values are the percentage of cell viability as relative to untreated cells. For the four fibroblast populations tested, $>90 \%$ of cells were viable after $48 \mathrm{~h}$ in the absence of staurosporine. Values are the mean $\pm \mathrm{SD}$ of three independent experiments in triplicate. $-\mathrm{O}-\mathrm{CDGla}-\mathrm{A} ;-\mathrm{CDGla}-\mathrm{B} ;-\mathrm{C}-\mathrm{Con}$ trol-1; $\triangle$ Control-2. * $p<0.05$ vs control. 


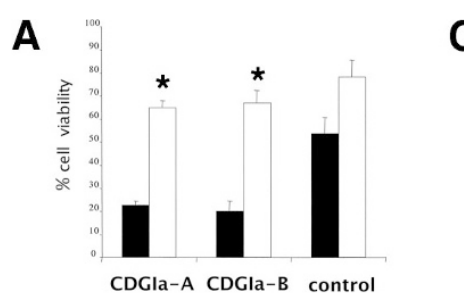

C

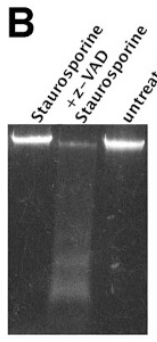

CDGla-A
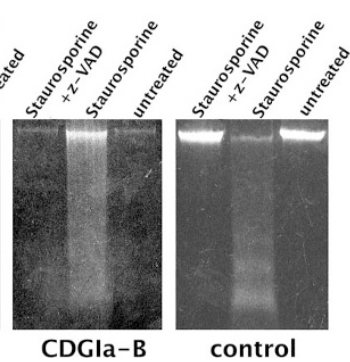

D

staurosporine

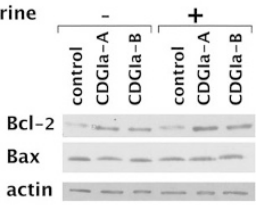

Figure 2. Analysis of hallmarks of cell death in control and staurosporinetreated fibroblasts. (A) Cells that were pretreated or not for $1 \mathrm{~h}$ with z-VADfmk $(100 \mu \mathrm{M})$ were incubated with staurosporine $(500 \mathrm{nM})$ for $24 \mathrm{~h}$. At the end of the incubation, cell viability was analyzed by the trypan blue exclusion test. $\square$, staurosporine treatment; $\square$, staurosporine treatment in presence of z-VAD-fmk. Values are the mean $\pm \mathrm{SD}$ of three independent experiments in triplicate. $* p<0.05 v s$ control. $(B)$ Analysis of DNA ladders by agarose gel electrophoresis in cells that were treated with staurosporine in the presence or absence of z-VAD-fmk. Cells were treated with or without staurosporine for $24 \mathrm{~h}$. At the end of the experiment, cells were lysed and homogenates were subjected to SDS-PAGE (7.5 or 15\%). (C) Expression of the cleaved forms of caspases 9 and 3 and PARP was analyzed by immunoblotting. (D) Expression of Bcl-2 and Bax was analyzed by immunoblotting. Expression of actin was used as an internal standard to verify that equal protein amounts were loaded.

(Fig. 2D). It is interesting that Bcl-2 is more highly expressed in CDGIa than in control fibroblasts. In addition, no difference in the expression of the proapoptotic protein Bax was observed among the various studied cell populations (Fig. 2D). Both Bcl-2 and Bax expression levels were not modified in the presence of staurosporine.

Mannose supplementation does not correct the CDGIa fibroblast sensitivity to staurosporine. After double labeling with $\left[2-{ }^{3} \mathrm{H}\right]$ mannose and $\left[{ }^{35} \mathrm{~S}\right]$ methionine, a lower $\left[{ }^{3} \mathrm{H}\right] /\left[{ }^{35} \mathrm{~S}\right]$ ratio is a characteristic of hypoglycosylation in CDG fibroblasts when compared with normal cells (13). Accordingly, we observed that the $\left[{ }^{3} \mathrm{H}\right] /\left[{ }^{35} \mathrm{~S}\right]$ ratio (normalized to protein content) is lower in both CDGIa-A and CDGIa-B fibroblasts than in control fibroblasts (Table 1). Another characteristic of CDGIa fibroblasts is the correction of the N-glycosylation defect by mannose supplementation. As shown in Fig. 3A, when incubated in the presence of $1 \mathrm{mM}$ mannose, both CDG

Table 1. Effects of mannose supplementation on synthesis of $N$-glycan chains

\begin{tabular}{lccc}
\hline & & \multicolumn{2}{c}{$\%$ endoH sensitive ${ }^{2}$} \\
\cline { 3 - 4 } Cell line & ${ }^{3} \mathrm{H}^{35} \mathrm{~S}^{1}$ & & $+1 \mathrm{mM}$ mannose \\
\hline Control & 100 & 77 & 74 \\
CDGla-A & 79 & $37^{*}$ & $69^{*}$ \\
CDGla-B & 76 & $56^{*}$ & $73^{*}$ \\
\hline
\end{tabular}

${ }^{1}$ defined as the percentage of control which is fixed as 100 .

${ }^{2}$ defined as the percentage of total TCA-precipitable ${ }^{3} \mathrm{H}$ released by endoH.

$* p$ value $<0.05$ when compared to control.
A B

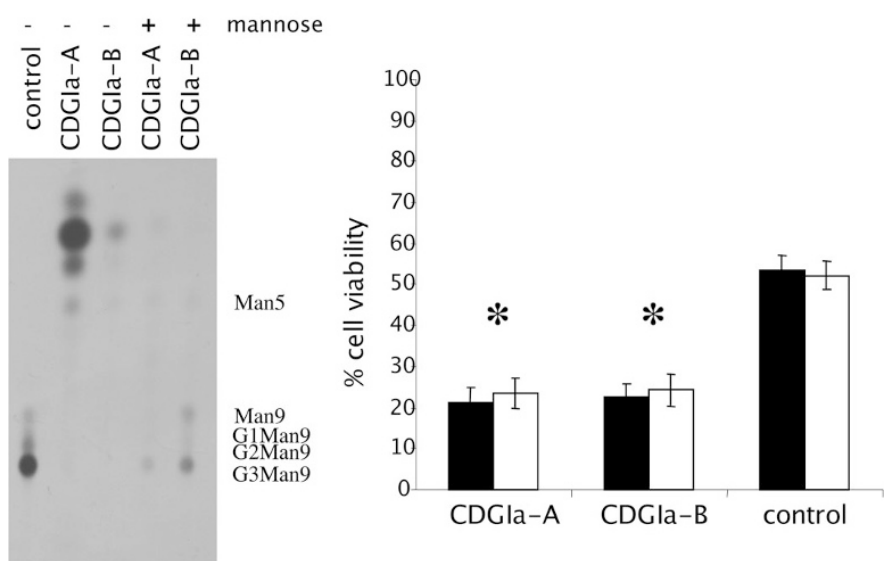

Figure 3. Effect of mannose supplementation on staurosporine-induced cell death. (A) Effect of mannose supplementation on LLO profile of CDGIa fibroblasts. Cells were pulse radiolabeled with $\left[2-{ }^{3} \mathrm{H}\right]$ mannose, and LLOs that were recovered from the chloroform phase were analyzed by TLC (as described in "Methods"). Where indicated, $1 \mathrm{mM}$ mannose was added 1 day before and during the labeling pulse. Note that the amount of $\left[2-{ }^{3} \mathrm{H}\right]$ mannose incorporation was lower when $1 \mathrm{mM}$ mannose was added. The LLO profile of control fibroblasts was not modified in the presence of $1 \mathrm{mM}$ mannose. $(B)$ Effect of mannose supplementation on cell viability. Cells were incubated in complete medium before the addition of staurosporine $(500 \mathrm{nM})$ for $48 \mathrm{~h}$. When required, mannose (final concentration $1 \mathrm{mM}$ ) was added $24 \mathrm{~h}$ before staurosporine treatment. Cell viability was analyzed by the trypan blue exclusion test. Values are the mean $\pm \mathrm{SD}$ of three independent experiments in triplicate. $\square$ staurosporine; $\square$ staurosporine + mannose. ${ }^{*} p<0.05$ s control.

Ia-A and Ia-B fibroblasts recover an LLO profile similar to the one of control fibroblasts. To investigate whether the sensitivity of CDGIa fibroblasts to staurosporine is related to an $\mathrm{N}$-glycosylation defect, we repeated the experiments reported above in mannose-supplemented cells. Mannose supplementation of CDGIa fibroblasts has been shown to increase the sensitivity of $\left[{ }^{3} \mathrm{H}\right]$ mannose-labeled $\mathrm{N}$-glycans to endo $\mathrm{H}$ by extending the length of high mannose oligosaccharides beyond five mannose residues $(14,15)$. Endo $\mathrm{H}$ digestion released 37 and $56 \%\left[{ }^{3} \mathrm{H}\right]$ mannose from CDGIa-A and CDGIa-B fibroblast glycoproteins, respectively (Table 1). By contrast, $77 \%$ of the radioactivity associated with $\left[{ }^{3} \mathrm{H}\right]$ mannose was released from control fibroblast glycoproteins. After mannose supplementation $(1 \mathrm{mM})$, endo $\mathrm{H}$ sensitivity of $\left[{ }^{3} \mathrm{H}\right]$ mannose-labeled glycoproteins was similar in CDGIa-A and CDGIa-B fibroblasts and control fibroblasts (see Table 1). However, despite the normalization of $\mathrm{N}$-glycosylation in CDGIa fibroblasts, their higher sensitivity to staurosporine-induced apoptosis was not reduced as exemplified by the analysis of cell viability (Fig. $3 B)$.

\section{DISCUSSION}

In the present study, we show that CDGIa fibroblasts are more sensitive to staurosporine-induced cell death than normal fibroblasts. Although PMM2 activity was slightly higher in CDGIa-B than in CDGIa-A, no difference in staurosporine sensitivity was observed between the two cell populations. As the same biochemical markers of apoptosis, i.e. caspases 9 and 3 activation, PARP cleavage, and DNA ladders are observed in 
both CDGIa and control fibroblasts, one cannot argue that the higher sensitivity to staurosporine is related to the existence of an alternative cell death pathway in CDGIa fibroblasts. The supplementation with mannose, which corrects the $\mathrm{N}$ glycosylation defect in CDGIa fibroblasts, does not modify their sensitivity to staurosporine-induced apoptosis, suggesting that their higher sensitivity to apoptotic stimuli is not a direct result of their $\mathrm{N}$-glycosylation defect. However, we cannot exclude that some glycoproteins involved in a cell-survival mechanism remain incorrectly glycosylated and inactive after mannose supplementation in CDGIa fibroblasts.

A default in protein $\mathrm{N}$-glycosylation is frequently associated with retention of glycoproteins in the endoplasmic reticulum (ER) (16). The accumulation of material in the ER can trigger an unfolded protein response characterized by the increased expression of protein chaperons such as Bip/GRP78 to relieve the accumulation of glycoproteins in the ER lumen (17). However, if the stress persists, then an ER-dependent cell death mechanism can be activated. According to previous reports (18), no difference in Bip/GRP78 expression was observed in CDGIa fibroblasts used in this study when compared with control cells in the presence or absence of staurosporine (data not shown). From this result, we can conclude that the higher sensitivity of CDGIa fibroblasts to apoptotic stimuli is not related to ER preconditioning.

Several enzymes of the metabolism of N-glycans have also been shown to be involved in the cell survival/cell death balance (19-21). DAD1 (defender against apoptotic cell death), a subunit of the mammalian oligosaccharyltransferase that transfers en bloc high mannose oligosaccharides onto polypeptides in the ER lumen, has an antiapoptotic activity via its interaction with Mcl-1, a member of the bcl-2 family (22). In contrast, overexpression of dolichol-phosphate-mannose 3/prostin-1, a small stabilizer subunit of the synthase, induces apoptosis in COS cells (21). Further studies will be aimed at addressing whether PMM2 is involved per se or through interaction with other proteins in the control of cell survival/ cell death balance.

Acknowledgments. We thank T. Dupré and N. Seta (Hôpital Bichat, Paris) for providing controls and CDGIa fibroblasts. Thanks are also due to S. Moore and Y. Pilatte for helpful comments on the manuscript.

\section{REFERENCES}

1. Van Schaftingen E, Jaeken J 1995 Phosphomannomutase deficiency is a cause of carbohydrate-deficient glycoprotein syndrome type I. FEBS Lett 377:318-320
2. Matthijs G, Schollen E, Pardon E, Veiga-Da-Cunha M, Jaeken J, Cassiman JJ, van Schaftingen E 1997 Mutations in PMM2, a phosphomannomutase gene on chromosome 16p13, in carbohydrate-deficient glycoprotein type I syndrome (Jaeken syndrome). Nat Genet 16:88-92 (published erratum appears in 1997 Nat Genet 16:316)

3. Jaeken J, Carchon H 2001 Congenital disorders of glycosylation: the rapidly growing tip of the iceberg. Curr Opin Neurol 14:811-815

4. de Lonlay P, Seta N, Barrot S, Chabrol B, Drouin V, Gabriel BM, Journel H, Kretz M, Laurent J, Le Merrer M, Leroy A, Pedespan D, Sarda P, Villeneuve N, Schmitz J, van Schaftingen E, Matthijs G, Jaeken J, Korner C, Munnich A, Saudubray JM, Cormier-Daire V 2001 A broad spectrum of clinical presentations in congenital disorders of glycosylation I: a series of 26 cases. J Med Genet 38:14-19

5. Matthijs G, Schollen E, van Schaftingen E, Cassiman JJ, Jaeken J 1998 Lack of homozygotes for the most frequent disease allele in carbohydrate-deficient glycoprotein syndrome type 1A. Am J Hum Genet 62:542-550

6. Freeze HH 2002 Human disorders in N-glycosylation and animal models. Biochim Biophys Acta 1573:388-393

7. Hansen SH, Frank SR, Casanova JE 1997 Cloning and characterization of human phosphomannomutase, a mammalian homologue of yeast SEC53. Glycobiology $7: 829-834$

8. Jaeken J, van Eijk HG, van der Heul C, Corbeel L, Eeckels R, Eggermont E 1984 Sialic acid-deficient serum and cerebrospinal fluid transferrin in a newly recognized genetic syndrome. Clin Chim Acta 144:245-247

9. Seta N, Barnier A, Hochedez F, Besnard MA, Durand G 1996 Diagnostic value of Western blotting in carbohydrate-deficient glycoprotein syndrome. Clin Chim Acta 254:131-140

10. Smith PK, Krohn RI, Hermanson GT, Mallia AK, Gartner FH, Provenzano MD, Fujimoto EK, Goeke NM, Olson BJ, Klenk DC 1985 Measurement of protein using bicinchoninic acid. Anal Biochem 150:76-85 (published erratum appears in 1987 Anal Biochem 163:279)

11. Bertrand R, Solary E, O'Connor P, Kohn KW, Pommier Y 1994 Induction of a common pathway of apoptosis by staurosporine. Exp Cell Res 211:314-321

12. Slee EA, Zhu H, Chow SC, MacFarlane M, Nicholson DW, Cohen GM 1996 Benzyloxycarbonyl-Val-Ala-Asp (OMe) fluoromethylketone (Z-VAD.FMK) inhibits apoptosis by blocking the processing of CPP32. Biochem J 315:21-24

13. Powell LD, Panneerselvam K, Vij R, Diaz S, Manzi A, Buist N, Freeze H, Varki A 1994 Carbohydrate-deficient glycoprotein syndrome: not an N-linked oligosaccharide processing defect, but an abnormality in lipid-linked oligosaccharide biosynthesis? J Clin Invest 94:1901-1909

14. Panneerselvam K, Freeze HH 1996 Mannose corrects altered N-glycosylation in carbohydrate-deficient glycoprotein syndrome fibroblasts. J Clin Invest 97:14781487

15. Korner C, Lehle L, von Figura K 1998 Carbohydrate-deficient glycoprotein syndrome type 1: correction of the glycosylation defect by deprivation of glucose or supplementation of mannose. Glycoconj J 15:499-505

16. Helenius A, Aebi M 2004 Roles of the N-linked glycans in the endoplasmic reticulum. Annu Rev Biochem 73:1019-1049

17. Rutkowski DT, Kaufman RJ 2004 A trip to the ER: coping with stress. Trends Cell Biol 14:20-28

18. Shang J, Korner C, Freeze H, Lehrman MA 2002 Extension of lipid-linked oligosaccharides is a high-priority aspect of the unfolded protein response: endoplasmic reticulum stress in type I congenital disorder of glycosylation fibroblasts. Glycobiology 12:307-317

19. Kelleher DJ, Gilmore R 1997 DAD1, the defender against apoptotic cell death, is a subunit of the mammalian oligosaccharyltransferase. Proc Natl Acad Sci USA 94:4994-4999

20. Makishima T, Nakashima T, Nagata-Kuno K, Fukushima K, Iida H, Sakaguchi M, Ikehara Y, Komiyama S, Nishimoto T 1997 The highly conserved DAD1 protein involved in apoptosis is required for N-linked glycosylation. Genes Cells 2:129-141

21. Manos EJ, Kim ML, Kassis J, Chang PY, Wells A, Jones DA 2001 Dolicholphosphate-mannose-3 (DPM3)/prostin-1 is a novel phospholipase C-gamma regulated gene negatively associated with prostate tumor invasion. Oncogene 20:27812790

22. Makishima T, Yoshimi M, Komiyama S, Hara N, Nishimoto T 2000 A subunit of the mammalian oligosaccharyltransferase, DAD1, interacts with Mcl-1, one of the bcl2 protein family. J Biochem (Tokyo) 128:399-405 